\title{
LA DIFUSIÓN DE LA CULTURA EN EL AULA DE ELE A TRAVÉS DE LAS SERIES DE TELEVISIÓN
}

\author{
Leticia López Martínez \\ Universidad Católica Juan Pablo II de Lublin \\ http://dx.doi.org/10.18778/8220-201-4.16
}

\begin{abstract}
Resumen
Este artículo trata el tema de la competencia cultural en la didáctica del español como lengua extranjera. En él se presenta el término cultura, se habla de los beneficios de su transmisión a través del video en clase y se muestra una aplicación práctica para llevar al aula con la serie Cuéntame como pasó. El objetivo del artículo es diferenciar entre los tipos de cultura dentro de una sociedad y exponer los distintos modos de aplicarlos en el aula de español como lengua extranjera a través de las series de televisión, una herramienta accesible que nos ofrece muestras de habla cercanas a la realidad.
\end{abstract}

Palabras clave: Cultura, didáctica del español, español como lengua extranjera, componente cultural.

\section{1.}

\section{Introducción}

La presentación del Marco Común Europeo de Referencia para Las Lenguas en 2001 originó un cambio en el planteamiento del aprendizaje de lenguas, añadiendo el componente cultural a los diseños curriculares. De este modo se afianzó la idea de considerar competencias relacionadas con el conocimiento cultural, pues dicho conocimiento se encuentra implícito en la lengua que se aprende. 
No se puede cuestionar que para ser eficiente en un idioma se deben dominar no solo las reglas del sistema lingüístico, sino también una serie de elementos no lingüísticos que lo acompañan y facilitan su expresión y comprensión. Algunos ejemplos son las pausas o las interrupciones, pero también es importante que los aprendientes adecúen su producción -ya sea oral o escrita- al contexto en el que se desarrolla. Estos elementos forman parte de la competencia sociocultural que se pretende que el alumno adquiera como complemento inseparable de la competencia comunicativa.

Sin embargo, resulta una tarea compleja de llevar a cabo en el aula. En numerosas ocasiones, los manuales vienen acompañados de audios o videos en los que se pretende dar una muestra lo menos artificial posible de la lengua, pero no siempre se consigue llegar a esa veracidad que se busca y que resulta más sencillo encontrar en el contenido audiovisual. Las series, en este caso, pueden resultar de gran ayuda para observar, analizar y entender todos esos elementos no lingüísticos mencionados con anterioridad y, además, suelen resultar una herramienta muy atractiva y amena en una sociedad guiada por imágenes como lo es la actual.

Las series no son un contenido creado para el aprendizaje de la lengua y es por esto por lo que la lengua en las series parece más real y el alumno pierde esa sensación de estar atado a estructuras fijas y previamente preparadas, como las que suelen estar acostumbrados a escuchar o ver en los manuales. Esta combinación de audio e imagen que encontramos en el video nos ofrece una infinidad de posibilidades que en combinación con la enseñanza tradicional puede resultar una herramienta de gran potencia en las aulas.

En este trabajo se describe el término cultura y su indiscutible relación con la lengua, se habla de los numerosos usos que podemos darle a la serie y el modo en que se debe realizar para evitar determinados problemas, así como de sus beneficios. Por último, se incluirá un ejemplo de actividad con una serie en particular: Cuéntame cómo pasó. 


\section{Estado de la cuestión}

\section{1.}

\section{El término cultura}

El término cultura es utilizado con diferentes acepciones por los hablantes de una lengua para describir el conjunto de modos de vida de un pueblo, tradiciones, conocimientos de diferentes campos, etc., y resulta complicado encontrar una definición que pueda agruparlas todas. Una de las más completas es la elaborada por Miquel y Sans (2004), a la que se hará referencia a lo largo del texto. Las autoras tomaron dos de las definiciones más conocidas de cultura: la de Harris (1990) y la de Porcher (1986), las unieron, modificaron y desarrollaron creando así un marco teórico de la palabra mucho más completo:

Resumiendo a Harris (1990) podríamos decir que la cultura es un conjunto aprendido/adquirido socialmente de tradiciones, estilos de vida y de modos pautados y repetitivos de pensar, sentir y actuar. Definición a la que podríamos añadir la de Porcher (1986): “Toda cultura es un modo de clasificación, es la ficha de identidad de una sociedad, son los conocimientos de los que dispone; son las opiniones (filosóficas, morales, estéticas...) fundadas más en convicciones que en un saber". Y, para completar este marco teórico, nos permitimos añadir que la cultura es, ante todo, una adhesión afectiva, un cúmulo de creencias que tienen fuerza de verdad y que marcan, en algún sentido, cada una de nuestras actuaciones como individuos miembros de una sociedad (Miquel y Sans, 2004: 328).

Del mismo modo, las autoras clasificaron el término cultura en tres tipos, entre los que se encuentran la cultura con mayúsculas, que hace referencia al conocimiento sobre hechos históricos, arte, historia, geografía y otras disciplinas, y la cultura a secas que "abarca todo lo pautado, lo no dicho, aquello que todos los individuos de una lengua y cultura comparten y dan por sobreentendido" (Miquel y Sans, 2004: 329). 
Con el fin de ser actores tan eficaces como lo son los hablantes nativos, los aprendientes de español como lengua extranjera precisan realizar en clase actividades que les permitan conocer qué tipo de comportamientos tienen los españoles en cada situación y cómo deberían, en estos casos, actuar ellos mismos.

Una actividad que resulta de gran ayuda para esta cuestión es la observación de situaciones concretas a través de las escenas de las series de televisión. De este modo es posible analizar no solo los elementos lingüístico, sino también aquellos no lingüísticos, y llegar así a conocer cada método o procedimiento que se realiza en los intercambios comunicativos de la vida cotidiana. Algunos ejemplos de enunciados extraídos de conversaciones reales que podrían analizarse son los siguientes:

1. Deje, deje. Esto lo pago yo (negociación a la hora de pagar una consumición)

2. Vivo en Velázquez, 24, 1. ${ }^{\circ} .^{a}$ (fórmula para dar la dirección en España)

3. ¡Qué monada! Se parece mucho a ti, ¿verdad? (la necesidad de hacer referencia al parecido de un bebé con los miembros de su familia)

4. Este es Carlos, el padrino de mi hija. Es un primo segundo mío (las explicaciones extensas que se suelen ofrecer en España incluso cuando se trata de una mera presentación rápida)

5. Oye, perdona la indiscreción, pero es que tengo un problema en el trabajo y necesito saberlo... ¿Tú podrías decirme aproximadamente cuánto gana una persona como tú? (las explicaciones con el fin de justificar preguntas consideradas tema tabú como lo pueda ser preguntar sobre la cuantía del sueldo) ${ }^{1}$.

"Todas estas observaciones no responden a reglas universales, sino que son propias de la lengua y de la cultura españolas" (Miquel y Sans, 2004: 330). Es decir, en otras lenguas y culturas, estas mismas situaciones tendrían otra respuesta por parte de sus hablantes y con mucha probabilidad, el estudiante de ELE actuaría del mismo modo que lo haría en su lengua, ya que es la referencia de la que dispone. Sin embargo, seguramente ese modo de

1 Ejemplos extraídos del artículo de Miquel y Sans (2004). 
actuación diste mucho del que se tendría en España y podría llevar al estudiante "a la inadaptación, a la inadecuación y, en definitiva, al fracaso en la interacción comunicativa” (Robles, 2002: 721).

\section{2.}

\section{El componente cultural en el aula de ELE}

Tal como se ha mencionado anteriormente, las competencias culturales no se incluyeron en los diseños curriculares hasta la publicación del Marco común europeo de referencia para las lenguas. $\mathrm{Si}$ bien es cierto que desde ese momento ha habido una mayor inclusión de los contenidos culturales en el aula, hay que clarificar que en la mayoría de los manuales aparecen en secciones separadas de la unidad, no siendo incluidos en el tema ni guardando una relación con el mismo. En cambio, para que el alumno conozca tanto el sistema de la lengua como su uso en la sociedad, "se ha de acercarlo a la cultura española a la vez que se le transmite los contenidos gramaticales, léxicos o fonéticos" (Robles, 2002: 722). Por su parte, los contenidos tratados en estos manuales están relacionados con la mencionada cultura con mayúsculas, que es de gran importancia, pero no es la única cultura. Además, en los últimos años se observa en los centros de enseñanza la división entre clases de lengua y clases de cultura. Y, ahora bien: ¿Acaso la enseñanza de la lengua está excluida de las clases de cultura? Y, por lo tanto, ¿no se pueden impartir clases de cultura a niveles bajos ya que en ellos no se domina la lengua?

En línea con esto último, se defiende que "existe una estrecha relación entre la cultura en la lengua y la lengua en la cultura ya que se trata, en suma, de elementos lingüísticos asociados a actuaciones, comportamientos y usos sociales" (Robles, 2002: 722). No obstante, la autora hace un pequeño inciso para mencionar que la diferencia radica en la dirección o determinación ya que cuando hablamos de la cultura en la lengua, hacemos referencia a que es la lengua la representación de las características culturales, mientras que cuando nos referimos a la lengua en la cultura "son los modos y hechos culturales los que se ven impregnados de determinados elementos lingüísticos” (ídem). 
De cualquier modo, queda claro que la enseñanza de una lengua extranjera no puede focalizarse exclusivamente en los contenidos lingüísticos, dado que la cultura y la lengua son componentes vinculados y dependientes el uno del otro: "La propia enseñanza lingüística contiene ipso facto una enseñanza cultural, puesto que en su condición de fenómeno la lengua representa en esencia uno de los principales aspectos de la cultura de una comunidad" (De Grève y Van Passel, 1971: 297). Por lo tanto, la escisión continua que apreciamos entre componente lingüístico y componente cultural en los centros de enseñanza carece de viabilidad debido al carácter indisociable que poseen ambos términos.

\section{3. \\ El video como herramienta en clase de español. Beneficios y usos}

"Las representaciones gráficas y audiovisuales han estado presentes a lo largo de la historia humana en diferentes campos y con diferentes funciones, pero siempre en la búsqueda de significación y de expresión artística y cultural" (Almeida y Fuentes, 2011: 83). No ha sido hasta hace apenas 40 años cuando la comunidad educativa se ha interesado por el video como recurso complementario en las clases de enseñanza de lenguas. No obstante, en los últimos años se ha apreciado la trascendencia de películas, series y otros formatos al mundo de la educación, funcionando como una muestra del "actuar y pensar humano" (Almeida y Fuentes, 2011: 83).

El cine cuenta con esa facilidad para representar el mundo y mostrarlo como si de la realidad misma se tratase. Se encuentra al alcance de cualquiera y tiene un gran poder de atracción hacia el alumno y es, además, probablemente, "el único recurso del que dispone el alumno en el aula para analizar con tiempo y detalle ese otro material extralingüístico que se da cita en la comunicación" (Montoussé, 2012: 80). Dicho material debería formar parte del tradicional esquema del modelo de comunicación de Jakobson, ya que: 
Todos estos elementos conforman el marco situacional en el que se encuadra todo intercambio comunicativo, y la red de relaciones que se establece entre ellos guía a los interlocutores en la realización de las inferencias necesarias para decodificar los mensajes y adoptar, al mismo tiempo, un papel determinado en el juego comunicativo (hablamos en serio, en broma, con ironía, con doble sentido, con ambigüedad...). Todos ellos deberán ser tratados en el aula de lengua si se pretende que el alumno sea capaz de comunicarse con éxito cuando salga de ella y se enfrente al mundo real (Montoussé, 2006: 356).

Si se pretende que el aprendiente analice cada elemento presente en la interacción comunicativa, tendría que estar presente en su transcurso. Sin embargo, dentro del aula esta práctica se torna complicada. Es por ello por lo que se aboga por el uso del material audiovisual y, en este caso particular, las series. La información que este transmite al espectador es mucho más valiosa que la de textos no audiovisuales debido a que "está semantizada, es decir, asociada a unos códigos que se dan cita en el discurso fílmico; no solo la imagen, también los diálogos, los sonidos, la música, los signos gráficos, etc." (Montoussé, 2012: 75). Todas estas características permiten ese acercamiento a la realidad, a lo cotidiano, y ofrecen tanto a profesores como a alumnos la posibilidad de crear un acto de habla lo más auténtico posible dentro del aula, con el fin de poderlo analizar en profundidad y llegar así a una aproximación y entendimiento de los modelos lingüísticos, pero, en especial, de los extralingüísticos. En otras palabras, ofrece una gran cantidad de información sociocultural que no pueden proporcionar otros materiales.

Y no solo esto, el video tiene también múltiples usos y diferentes aplicaciones en el aula: puede actuar como elemento motivador con el fin de "provocar una respuesta inmediata, estimular la participación o promover actitudes de investigación” (Hernández, 1998: 217). En este caso el video debe tener una duración máxima de 10 minutos y debe funcionar como punto de partida de la clase para dar pie al debate o para despertar el interés de abordar el tema que se ocupa en esa lección; también como apoyo en clase, respaldando las explicaciones del docente, para recapitular y así 
reforzar lo que ya se ha aprendido o como cierre de una unidad presentándose como "último momento de estrategia didáctica, haciendo las veces de síntesis y favoreciendo la obtención de conclusiones" (ídem).

Resumiendo, son muchos los beneficios que nos brinda el video en el aula: motiva, facilitando la participación, permite trabajar tanto elementos verbales como no verbales, es un soporte que se encuentra al alcance de los alumnos, permite contextualizar los elementos lingüísticos y adentra la vida real en el aula.

\section{4.}

\section{Cuéntame cómo pasó. ¿Por qué esta serie?}

Las series españolas han contado siempre con actores de primer nivel y han gozado de éxito tanto dentro como fuera de nuestras fronteras, prueba de ello es que muchas han sido y están siendo televisadas fuera de España. Una de las últimas en unirse al elenco de series que han atravesado fronteras ha sido Cuéntame cómo pasó, cuyos derechos han sido comprados recientemente por la productora New Media Vision que se encargará de su adaptación bajo el nombre Remember when ${ }^{2}$.

Nuestras series constituyen un vehículo que nos ayuda a mostrar al mundo lo que somos y cómo somos, por tanto, ¿por qué no explotarlas en la clase de ELE y hacer del aprendizaje algo más ameno? En este trabajo se ha decidido tomar una serie en concreto como ejemplo de explotación: Cuéntame cómo pasó, una serie que pretendía narrarnos la historia de nuestro país en los años 60 a través de una familia de clase media y todavía continúa en escena después de habernos contado 20 años de historia de España. Se trata de una serie que apuesta por la historia y la cultura nacional, que propone tramas innovadoras y temas innovadores dentro de la televisión, que sigue dejando al espectador con la boca abierta temporada tras temporada, que emociona, que engancha y que no deja indiferente

2 Información extraída de http://www.mediatrends.es/a/36234/series-espanolas-en-estados-unidos/ y http://elpalomitron.com/remember-when-version-estadounidense-de-cuentame/ 
a nadie. Por todo ello se defiende su uso en diferentes niveles y se han elaborado actividades para cada nivel que utilizan la serie como herramienta de apoyo. El objetivo general que se persigue con esta batería de actividades es mostrar las diversas posibilidades que ofrecen las series como instrumento pedagógico para practicar las cinco destrezas haciendo que el aprendizaje de español como lengua extranjera sea significativo. Asimismo, la serie ofrecerá al alumno un fuerte input de carácter cultural y, por ende, lingüístico.

\section{3. \\ Conclusión}

En la actualidad la enseñanza de idiomas se encuentra en un momento de renovación, el enfoque comunicativo se ha hecho un hueco en este mundo y las nuevas tecnologías no paran de desarrollarse ofreciendo a los docentes numerosas herramientas prácticas de gran utilidad en clase. Son muchos los casos en los que se explotan películas de habla hispana con una batería de actividades para la práctica de contenidos ya vistos en el aula o la presentación de algunos nuevos. Sin embargo, las series son un material que todavía no se ha aprovechado lo suficiente y que ofrece muestras de habla muy cercanas a la realidad que sirven de ayuda, sobre todo, en casos en los que el alumno no se encuentra en inmersión en el país de habla hispana.

En este trabajo hemos utilizado las series, en concreto la serie de RTVE Cuéntame cómo pasó, como herramienta para integrar cultura y aprendizaje lingüístico en la clase de E/LE de una manera más amena y entretenida. Se pretende demostrar la cantidad de recursos de los que disponemos, accesibles y cercanos a todos $y$ que nos pueden servir como un soporte fundamental en el aula a la hora de ofrecer muestras de habla próximas a la realidad.

Abogamos por la inclusión de las series en las clases de ELE a través de esta u otras propuestas y, de este modo, seguir creando una comunidad más fuerte y potente que día a día crezca y se renueve, tal como lo hace nuestra sociedad. 


\section{4.}

\section{Muestra de aplicación didáctica de la serie Cuéntame cómo pasó}

A continuación, se ofrece una pequeña muestra de la aplicación didáctica propuesta que en total consta de 20 actividades ${ }^{3}$.

\section{Actividad 1}

\begin{tabular}{ll}
\hline Nombre de la actividad & Cuéntame sus rutinas \\
\hline Nivel & A1-A2 \\
\hline Objetivos & $\begin{array}{l}\text { Practicar las rutinas diarias. } \\
\text { Fomentar el interés por los } \\
\text { personajes y por los actores que los } \\
\text { interpretan }\end{array}$ \\
\hline Destrezas practicadas & $\begin{array}{l}\text { Expresión oral y escrita } \\
\text { léxicos y gramaticales }\end{array}$
\end{tabular}

3 Para la presentación de nuestra batería de actividades utilizaremos el modelo usado en la revista electrónica dedicada a la enseñanza de Español como Lengua Extranjera RutaELE. 
Los alumnos verán fragmentos cortos de la serie sobre las rutinas de cada personaje y deberán elaborar una producción escrita que después compartirán con sus compañeros. Procedimiento Deberán describir cómo son los personajes, qué les gusta hacer, a qué hora se levantan, con quién viven, etc. Según el nivel, sería interesante preguntar qué los ha llevado a pensar eso para así ayudarles a reflexionar y aprender a expresar los motivos.

\section{Referencias bibliográficas}

Almeida, E. y Fuentes, A. (2011)," El uso de materiales audiovisuales en la clase de Español como Lengua Extranjera: Implementación de una propuesta didáctica", Revista Docencia Universitaria, $81-132$.

De Grève, M. y Van Passel, F. (1971), Lingüística y enseñanza de lenguas extranjeras, Madrid: Fragua.

Hernández Luviano, Guadalupe (1998), "El vídeo en el aula”, en Didáctica de los medios de comunicación. Antología, México D. F.: SEP, 207-222.

Miquel, L. y Sans, N. (1992), "El componente cultural: un ingrediente más en las clases de lengua", RedELE, 15-21.

Montoussé, J. (2006), “Tendiendo puentes de conocimiento: el cine en el aula de lengua extranjera", [en línea] $<$ http://cvc.cervantes.es/lengua/anuario/anuario_06-07/pdf/ele_02.pdf $>$, [fecha de consulta: 04.05.2018].

Montoussé, J. (2012), “¿Qué hago con esta película?: usos y valor del cine en el aula de ELE” [en línea] <http://cvc.cervantes.es/ensenanza/biblioteca_ele/publicaciones_centros/ PDF/argel_2012/07_montousse.pdf >, [fecha de consulta: 04.05.2018].

Robles, S. (2002), "Lengua en la cultura y cultura en la lengua", Actas XIII ASELE,. Murcia, 720-730. 